\title{
11
}

\section{"Global Jinzai," Japanese Higher Education, and the Path to Multiculturalism: Imperative, Imposter, or Immature?}

\author{
Julian Chapple
}

\subsection{Introduction}

Japanese society has, at various times throughout its history, been led in different directions by state policy makers' catch phrases. The final societal destination of these slogans has changed to suit the needs of the times, but their reoccurrence and importance can neither be denied nor overlooked. Phrases and slogans such as sonnō-jōi (Revere the Emperor, Expel the Barbarians), fukoku kyōhei (Enrich the Country, Strengthen the Military), tōyō no dōtoku, seiyō no gakugei (Eastern Ethics, Western Science), wakon yōsai (Western Learning, Japanese Spirit), bunmei kaika (Civilization, Enlightenment) and dastua nyūo (Leave Asia, Join the West) are all examples of "battle cries" behind which society was rallied in order to rid itself of some seemingly corrupting influence or to adopt systems in order to make a radical change in direction. More recently, while arguably less provocative in nature, catch phrases have continued to be employed to focus national attention on goals deemed important by the nation's state-makers today. Here, words like kindaika (modernization), ōbeika (Westernization), kokusaika (internationalization), and gurōbaruka (globalization) have adorned official documents and the media reflecting the needs or goals of each respective period (Chapple, 2002).

While by no means solely limited to the education sector, as education is often considered the "cornerstone of all social systems" (Ministry of Education, Science and Culture 1999, 2), it is here that these national slogans and phrases have been utilized most successfully and have influenced the greatest number of policies and people. Since its inception in 1873, Japan's highly centralized modern education 
system has been used to disseminate official state philosophy well beyond the confines of the classroom, designed to change society in often dramatic and drastic ways. The fact that it remains comparatively top-down and uniform has contributed to the successful spread and social-consciousness permeation of slogans and their goals. It is through the education system that the government's ideals are promulgated and therefore a vehicle that reflects policy directives which are not always as simplistic or innocuous as their succinct slogans make them appear.

In the same vein as terms from eras gone by, one of the keywords in higher education in Japan today relates to the development of so-called "global jinzai" (global personnel or human resources). This chapter, through an examination of the background and goals of this latest term, aims to assess whether it represents a prerequisite for something worthwhile in Japanese society, is merely a guise serving some alternative purpose, or is in fact an (unsophisticated) attempt to achieve something beyond its reach. Through an examination of the situation, goals and actions taken in the name of fostering global jinzai, much can be learned of the (real?) motives behind the phrase. Ostensibly arising from a need to interact with larger numbers of non-Japanese in various situations and localities, global jinzai can be interpreted as Japan's equivalent attempt at what is often referred to as "global competence" in other countries, in order to deal with an increasingly interconnected world outside and a growing multicultural society at home.

The chapter argues that while outwardly the motives and goals of creating globally competent human resources and fostering internationalization appears seemingly straightforward (Knight \& Altbach, 2007), different groups have somewhat differing — at times even contradictoryagendas. Thus, rather than functioning as a potential pathway towards multiculturalism, the global jinzai slogan is merely a vehicle for long sought after reform (particularly with regard to the English language and universities in general) reflecting a reality of Japanese society. In short, what is really being discussed are the fundamental changes in educational philosophy and structure required to enable development in a "globally competent" direction. Finally, it concludes by questioning whether this ongoing push really will, or can, lead to the expectations that many have, given the entire debate's immaturity and deficiencies in terms of being capable of fostering global citizens able to adapt to a more multicultural society. 


\subsection{What are global jinzai?}

To understand what is generally referred to by the term global jinzai requires an appreciation of the situation facing Japanese society today. As in times past, which resulted to slogan-led plans, global jinzai is born out of a need to react to the external environment. In this case it is the twin forces of a desire to increase Japan's political presence on the global stage and strengthen its economic position internationally in the face of growing, diversified, and rapidly changing competition. Like all developed nations, the ability to be able to sell products in today's dramatically evolving world requires skills and abilities different from those of even just a few years ago. Consequently, education aimed at fostering globally competent human resources is something that most countries are today actively seeking.

This fact is evidenced through a quick Internet search, which reveals over 10 million hits related to the term "global jinzai" in Japan. It is used and discussed in the media as if its goals are clear and its focus defined. Yet, in spite of its seemingly constant recent media use, "global jinzai" continues to remain somewhat of a vague term, something akin to the term "leadership" in English, "a term which everybody knows, but for which there are countless definitions" (Pollock, 2012, p. 1). However, unlike slogans of the past, global jinzai encompasses a number of measurable qualities making it unique, a point addressed later.

One seemingly all-encompassing definition of global jinzai is the following, from the Joint Business-Academia Committee for the Promotion of Global Jinzai Development, which claims that global jinzai are:

people who, in today's competitive and cooperative world, can-while maintaining their sense of Japanese identity - possess a broad worldview based on both general and specialized education, have communicative and cooperative abilities to build relationships which go beyond values, cultures and different languages, and that have the ability to create new values and the desire to contribute to society now and in future generations. (Author's translation and emphasis added) ${ }^{1}$

Another even more quantifiable definition can be found in the mid-term report (released in June 2011) of the Japanese Ministry of Economy, Trade and Industry (METI)'s Council on the Promotion of Global Human Resources, which claims that global jinzai comprise three categories (METI, 2011). The first is language proficiency and communication skills, and is the most detailed. The second category encompasses 
features such as an independent (shutaisei) active (sekkyokusei) attitude, a spirit of challenge, a harmonious (chōwasei) and flexible (jyūnansei) spirit, and a sense of commitment (sekininkan) and responsibility (shimeikan). The third category is the requirement for cross-cultural understanding and, once again, cultural identity as a Japanese.

While at first glance these both appear to be well-prepared definitions, they do pose a number of concerns. Explained this way, global jinzai is an outward-looking concept (similar to Japan's version of the concept of internationalization, kokusaika) and fails (perhaps purposely) to examine the requisite systemic changes required domestically. In other words, by focusing attention on the capabilities required for work abroad, the debate about the changes required to accept greater diversity within Japan are in effect quietly overshadowed and even nullified. Hence, acceptance of, and policies towards, multiculturalism are not seen as things that need to be considered. Global jinzai requires an international curriculum and it is here too that the link with internationalization is again apparent. Yet the difference seems to be an overwhelming feeling that by sending students abroad such talent can be fostered; it is not something that can be easily nurtured domestically. This most likely stems from the fact that multiculturalism is seen as something that exists in other settings (rarely in Japan) and therefore the required special skills can only be fostered overseas.

A second point of concern is that language skills can at least be "measured" using standardized achievement tests, while the other two categories are subjective and consequently extremely difficult to both foster and gauge. This probably explains why they are usually overlooked for the more easily identifiable "language ability" and there is such scant information regarding how exactly to foster them. This point will also be returned to later.

A third point of concern is the final category of cross-cultural understanding and cultural identity "as a Japanese" which reads almost as an oxymoron. While naturally understanding one's cultural identity is an important prerequisite and base for cross-cultural understanding, it is dubious to assume that this is something that can be taught at higher educational levels. Surely these are things that should take place at the lower levels of the educational ladder (if at all), and the need to reiterate it speaks volumes of the desire to protect the status quo. Similarly, the assumption that one's identity as a Japanese is a fixed concept that is required to be stressed first almost contradicts the very philosophy behind the entire global jinzai process itself. Yet, at a symposium organized by the Sankei Shimbun newspaper in 2012, three 
of the four expert panelists mentioned the need to understand and promote Japanese identity (Sankei Shimbun, 2012). Hence the term is at risk of being hijacked by those with agendas which may be opposed to the concept of internationalism. In short, global jinzai may merely represent another way of strengthening Japanese identity in reaction to a perceived outward threat. If not, one would expect there to be clear action and results suggesting the contrary. Evaluated this way, the slogan fits the mold of similar slogans of the past and falls into a kind of "sanctioned, but confined reform" category (i.e. educational reform sanctioned by the government but which falls within clearly stipulated confines-in this case firmly stressing and retaining "Japaneseness" as a prerequisite). However, ensuring that the promotion of a global mindset is predicated on the maintenance and reassurance of a Japanese identity is a very un-nuanced reality of what an individual is, and not only points to an ongoing heavy dose of social control, but is also a reflection of insecurity in allowing a total opening to the world. In other words, the development of global citizens (detailed later), which I argue is a more useful, important, and necessary goal of internationalization, is virtually untenable in Japan under present restrictions.

In other fields in Japan we can find different definitions: for example, those from both the Japan Business Federation (Keidanren) and the Council on Competitiveness Nippon (COCN), which do not include references to Japanese identity. However, this is likely because they are solely concerned with skills like negotiating with customers and business management and are merely reflections of what most other countries refer to by the concept of global jinzai and are beyond the scope of this chapter. Thus, the concept being pushed by MEXT appears to mask a few ulterior motives.

It is also interesting to note that, as mentioned, the development of skills deemed necessary for productivity in this global age are by no means the sole domain of Japanese educators. Rather, it is truly itself a global trend. However, when compared with definitions of what skills a globally competent person should have, the inadequacy of the predominant definitions in Japan is striking. In addition to mastering a foreign language and a different culture and geography, fluency in things like e-commerce, the Internet, knowledge of political and economic systems of other countries, and familiarity with global issues are also often stated as important (Ouyang \& McAlpine, 2013). What is more, rarely do non-Japanese definitions of global competency skill requirements make much reference to an individual's sense of cultural and national identity as a prerequisite for functioning in a multicultural setting. 


\subsection{Background-why now?}

Why has there been such an interest in the concept of global jinzai of late? After all, other than the slogan itself, nothing in the content of the concept is particularly ground-shaking or revolutionary. For decades now, Japan's leaders have been singing a similar tune and preaching the need for greater collective international skills. In 1997, for example, a special committee on education formed within the Japan Business Federation submitted a report entitled "Fostering Human Resources Capable of Contributing to the Global Society." ${ }^{2}$ Claiming that dealing with a globalizing society is now a "matter of urgency," the report outlined four requirements of such human resources, namely: independence, respect for and understanding of difference, foreign language abilities to communicate with non-Japanese people, and specialist skills. Almost two decades later virtually the same skills are still considered a matter of urgency. So what exactly is different this time?

Until recently, an impressive image of Japanese businessmen traveling the world as a part of their jobs has permeated the media. Today, however, with a decline in the number of young Japanese studying abroad, and the world becoming more interdependent than ever before, there is seemingly a lack of Japanese willing (and perhaps able) to venture abroad in order to forward the nation's economic hopes. It is these twin factors-an increasingly "inward-looking mentality" of young Japanese coupled with the greater and diversifying international desires and needs of Japanese manufacturers and leaders-that has rekindled this entire debate recently.

\subsubsection{An inward-looking trend}

Since peaking at 82,945 students studying overseas in 2004 , with the exception of the number of Japanese leaving to study in China and India (which has shown an increase), the overall number has been on the decline. The latest available statistics show that the number dropped $3.1 \%$ from the previous year (the sixth continuous year-on-year drop) to 58,060 in 2010 (Nihon Keizai Shimbun, 2013b). There are a number of reasons that have contributed to this decline. Firstly, the financial costs of study abroad (particularly in OECD nations) have risen dramatically over the past two decades. A second factor is language ability. While many students study abroad to improve their foreign language skills, usually that is all they are able to accomplish in the time away. In other words, taking regular classes at an overseas university, joining an internship program, or other such activities are usually out of the question. Thirdly, and 
related to the second point, due to increasing language requirements, the required educational level and corresponding academic motivation of Japanese students are also contributing factors. Fourthly, many Japanese universities are not well prepared to deal with students who do study abroad in terms of providing academic recognition of their study. Finally, a growing number of students ironically actually see study abroad as a disadvantage in finding employment in Japan, given the narrow and limited recruitment timeframe and differences in academic calendars. In short, the attitude towards study abroad-and indeed career planning itself today in Japan-is in flux, resulting in a growing gap between societal (particularly parental) expectations and those of the business world.

In a survey conducted in March 2013 by the Institute for a Global Society, $50 \%$ of high school students and $55 \%$ of university students surveyed responded that they felt it was too late for them to become globally active citizens, even if they started receiving education now to learn how to deal with a globalizing world (The Japan Times, 2013).

\subsubsection{Future demand for global jinzai}

As new technologies make rapid economic growth and development possible in more remote places and on an unprecedented scale, more than ever before developed nations need to keep pace in order to avoid being left behind. Based on present trends, Japan may be unable to take advantage of emerging growth in the newly expanding BRICs (Brazil, Russia, India, China) or VISTA (Vietnam, Indonesia, South Africa, Turkey, Argentina) regions without greater numbers of globally competent employees. Furthermore, Japan can no longer rely on a model in which only a handful of top, elite executives are responsible for global business success. Given the nature of the evolving global economy it is no longer only the large multinationals that require more globally competent staff, even "domestically-focused companies and small businesses are feeling the need to become more global" (Pollock, 2012, p. 1). And, for Japan to be able to play a greater, more proactive role-commensurate with its economic size-on the world stage, helping towards the solution of global problems, a much larger cross-section of society needs to be aware, interested, and involved in global issues on a regular basis.

Yet, at present, according to a survey of Japanese companies published in 2012, sponsored by Japan's Ministry of Education, Culture, Sports, Science and Technology, only around 1.68 million Japanese can be classified as globally competent jinzai (MEXT, 2012). It is estimated that demand for global jinzai by Japanese companies will grow by a 
massive $240 \%$ over the next five years (from 2012 and 2017), equating to around $8.7 \%$ of the entire employed population (ibid.). The good news is that, according to the aforementioned survey, $30 \%$ of university students and $40 \%$ of high school students said they want to become an active participant in the global society, but they just do not know how to do it (The Japan Times, 2013). Hence the urgency this time is greater than at any time in previous decades.

\subsection{Extenuating reasons: An imposter in the policy?}

However, there are other reasons behind the push for global jinzai than the above-mentioned predominantly business-oriented ones. A brief examination of these, and their respective agendas, reveals a familiar feature of educational policy in Japan that could be termed "Trojan horse change."

In addition to the concerns voiced in the business world, the global jinzai debate reflects a common sense of urgency within Japan that higher education is no longer serving the needs and goals of society, and consequently that Japan is being rapidly left behind. With Japan's eighteen-year-old-population rapidly declining, the need to seek alternative sources to contribute to the overall student pool has also become an important task. Foreign students have been targeted as one such possible source. To this end, in 2008 the government set a target of 300,000 international exchange students in Japan (a figure equivalent to approximately $10 \%$ of the entire Japanese student population) by 2020 , a proposal more daring than its predecessor of 100,000 by 2000 (which was not in fact achieved until 2003 and then only as the result of an easing of regulations related to application and visa procedures).

Still, more pessimistic voices point out that $45.8 \%$ of private fouryear universities were unable to fulfill their student quotas and had to rely on students from Asia to make up the shortfall or risk bankruptcy (Sawa, 2013). What is more, Japanese companies today are not only recruiting or relying solely on Japanese students. "There was a shared understanding between the Japanese business sector and the government that Japan needed to recruit talented students to succeed in international competition" (NIER, 2011, p. 3). Further, today, those students are being actively sort globally. Thus, global jinzai represents a "Trojan horse" attempt at university reform in order to increase international student numbers, internationalize the curriculum and faculty as well as to hopefully boost international rankings in the long-term (MEXT has set a goal of having ten Japanese universities ranked in the top 100 worldwide by 2020). 
Yet Japan is competing in an increasingly competitive and expanding market, not only for global talent but also for international students. According to the OECD (2012), over the past three decades the number of international students has increased fivefold from 0.8 million worldwide in 1975 to 4.1 million in 2010. Not only is Japan's popularity as a destination a questionable factor (not being an English-speaking country, where by far the majority of students are heading), the figures also reveal that other countries' students are more active than Japanese students, meaning that they are becoming globally competent employees in greater numbers and contributing to their respective countries' growth and development. In short, Japan is facing intense competition on various fronts (NIER, 2011). Reform is recognized as a matter of urgency, but is not something that can easily be achieved.

\subsection{Nothing more than English?}

Returning to the fact that, of the three identified core components of global jinzai, only language skills are measurable, it is only here that anything resembling policies or plans actually exists at present. This likely stems from the reality that nationwide English language abilities are still not where the Japanese government would like them to be. In international TOEFL rankings in Asia, Japan is 27 th out of 30 nations, and scores for other tests are not much different. Consequently, the global jinzai discussion comes at a crucial time for Japan, with other debates pertaining to English (i.e. foreign language) education in elementary schools, teacher licensing, and so forth also coming to the fore. In other words, global jinzai provides a useful smokescreen behind which discussions and even changes, particularly related to English language, can be ushered in under a sense of imperative.

In a recent concrete proposal, MEXT has announced that it plans to develop 100 "Super Global High Schools" from spring 2014, which will represent a new type of high school tasked with fostering global leaders who can deal with the world (Oka, 2013). These schools will place greater emphasis on English and other foreign languages while at the same time stressing problem analysis and problem-solving abilities as well as educating about culture and history. Perhaps the most striking feature of the proposal is that they will be classed as "exceptional schools" in terms of the national curriculum guidelines, and thus when necessary will not be bound by traditionally rigid rules.

Yet what such a policy proposal reveals in reality is, firstly, MEXT's lack of imagination (Super English Language High Schools [SELHis] 
were created in 2003 in an effort to improve the English language ability of Japanese high schools students, but have not led to striking results), and, secondly, once again it is really only English that is important. The fact that these schools will be an exception and not the norm points to the fact that it is after all only the elite who are being fostered. Finally, indicating that they may even be exempt from national curriculum restrictions, meaning they are stepping outside the norm in terms of what they offer, reflects the extent of the restriction that the present curriculum poses. Surely, if the goal was to foster Japanese with global competencies, then such options should be the norm offered to all the population. Furthermore, there is no public discussion about the role of languages other than English in the national curriculum, even though Japanese society today is far from the monolingual one it portrays itself as (Lie, 2004; Maher \& Yashiro, 1995).

\subsubsection{Aiming for the top: Global jinzai and university reform?}

If we examine the action plans towards creating such global talent, as laid out by MEXT in its recently published proposals for reforming universities in order to make them "an engine for social change" (MEXT, 2012, p. 11), there are in fact scant references to the issue of global jinzai. Five goals and two plans are listed, the majority of which are aimed at institutional change, and this, again, probably ultimately reflects MEXT's real motive behind the debate on global jinzai. ${ }^{3}$ Radically trying to change Japan's universities by first raising public and business awareness of the gap between present and desired higher education is an effective tool, followed by incentives to change.

The results to date, however, have been far from stunning. The much heralded "Global 30 " 4 presently number only 13 , and other than these, most universities are either struggling or see little incentive to radically internationalize their campuses other than the usual cosmetic changes. In reality, even a full implementation of the proposals that MEXT is suggesting is hardly likely to lead to any significant advance in overall standings of Japan's higher educational institutions on any global index. Further, it is unrealistic to expect universities to shoulder the burden of creating such future labor alone. It requires a concerted change in the compulsory education curriculum in general, greater emphasis on career education and more system-wide flexibility.

In order for global jinzai to become a driving force for educational reform at the top, changes are required, particularly in terms of educational quality, content, and the system itself. Firstly, faculty must themselves become more "globally competent," experienced, or at the very least, inclined. 
This is not necessarily the case. University teachers in Japan are often criticized for being insular and inward-looking. Some are even opposed to having students study abroad (Nihon Keizai Shimbun, 2012). Unlike in many other developed countries, where competition and deregulation have led to enormous - at times incredulous - changes, today in Japan the notion of promotion based on seniority and lifetime employment, hinder greater openness and innovation (Nihon Keizai Shimbun, 2013a). Further, a lack of commitment by university leaders means that this trend will likely continue for the immediate future. Actively advertising internationally is one option, yet it requires a system in place to accommodate such talent as well as the ability for them to offer classes in, once again, English. Yet the creation of such a system is predicated on acquiring consensus and recognition among the Japanese populace that their country is now a multicultural society. This in turn requires an education system that actively acknowledges such a concept and educates accordingly. As a recent editorial in The Japan Times (2013) stated:

Unfortunately, even when the curriculum is globalized and when broadening experiences like study abroad are undertaken, the teaching methods at most universities, as well as secondary schools, remain mired in one-way, teacher-centered approaches that do not help students acquire confidence, communication skills or a broader understanding that they need for engaging in international situations.

In an effort to bring greater clarity to the needs of global jinzai, a number of reports have already been released. A mid-term report released by the LDP's Financial Reform Group recommends doubling the present number of native English speaking teachers in Japan to 10,000 within three years, and to be able to send one to every elementary, junior, and senior high school in the country within ten years (Nihon Keizai Shimbun, 2013c). Similarly, as mentioned above, MEXT recommends increasing the number of foreign faculty in Japan's universities (although no concrete plans or details have been made yet) in plans which resemble the oyatoi gaikokujin (hired foreigners) project of the Meiji era, and consequently the hope of it leading to lasting changes is remote. Once again, the focus is on English and the concern is about reforming universities and on general language skills in particular.

In terms of systematic changes, a number of issues are pertinent. The development of global jinzai requires an international curriculum, and it is here too that the link with internationalization is again apparent. 
Yet the difference seems to be an overwhelming feeling that by sending students abroad can be fostered such talent; it is not something that can be easily nurtured domestically. This most likely stems from the fact that multiculturalism is seen as something that exists in other settings but rarely in Japan, and special skills are required for people to be able to adequately deal with it. Such skills can only be fostered overseas. A commitment to making classes of an international standard and offering flexibility in academic calendars (the likes of the touted "Gap Year Project," Ashizawa, 2012) are two possible options. Here "international standard" does not mean to imply that present levels are necessarily low, rather that the systems supporting the curricula are not international. For example, the numbering of classes (to facilitate cross crediting) is undertaken by only around $7 \%$ of the nation's universities (Nihon Keizai Shimbun, 2012). Because global jinzai requires intercultural communication abilities and a greater understanding and acceptance of diversity (a fundamental of multiculturalism), there is also an urgent need to internationalize campuses in Japan to provide for such learning opportunities for those students unable (or unwilling) to study abroad, or for those who return to further hone their skills. More use of dual degrees, offering greater diversity in international programs (volunteer abroad, international internships, and so on) could be faculty- or university-wide possibilities. Meanwhile, at the class level, providing greater evidence of student learning which is internationally compatible (learning outcome assessment, portfolios, etc.) is another option.

Without doubt, the fostering of global jinzai has become a foundation stone of numerous policy initiatives and even the driving force behind the creation of some new faculties. Yet global jinzai refers to multi- and interdisciplinary skills usually acquired from disparate departments. Rather than new faculties, it would be more appropriate to give greater consideration to the offering of courses or qualifications that span disciplines and/or departments. Further, to lead to the fostering of global citizens, a much more transparent, focused, and open curriculum is required than exists at present. This leads on to a final question: is the ongoing push for global jinzai-however its goals are defined-an outdated and inadequate policy nowadays anyway?

\subsection{Conclusion}

The global jinzai slogan appears to be one aimed at pressing society to become more outward-looking and, in particular, English languagefocused. Put simply, state goals like economic development and domestic 
growth require Japan to interact on a greater scale internationally. People are required to change, which inherently requires a reexamination of the role of the individual in society. Global jinzai must be players for "Corporate Japan" on a global stage, yet be able to think and act as individuals in one-on-one exchanges. Thus, global jinzai should ultimately lead to changing business structures in Japan that will in turn affect the education system and consequently all aspects of society. In short, in order to create global jinzai, the fundamentals of education, particularly its ultimate goals and the aims of state-making, will need to be reevaluated. The long-standing traditional group model is unlikely to support, or lead to, the creation of such human capital, because the world today is more complex than textbooks lead us to believe.

As a policy driver, global jinzai represents a massive push for Japan. Perhaps it may eventually even become a kind of "black ships" event for education in Japan, reminiscent of the fleet accompanying Commodore Perry that heralded in the modern age for Japan and its increasing interaction with other nations. That possibility remains, but, as I have attempted to outline, at present it is difficult to see it emerging. Whether global jinzai actually becomes a touchstone for change or merely joins the scrapheap of used slogans remains to be seen. And it may even be a moot point in the long term.

The ideal encapsulated in the term "global jinzai," despite the cosmopolitan and universal image it portrays, is fast becoming more and more irrelevant. Ouyang and McAlpine point out that the ultimate goal of educational internationalization is global citizenship-“"the most important political and philosophical concept since the idea of the free, equal individual with rights" (Ouyang \& McAlpine, 2013, p. 10)-and that global competency alone is not necessarily likely to achieve this. Thus, in spite of the best efforts by Japan's educational policy leaders and experts, the entire debate relating to global jinzai is highly unlikely to lead to any fundamental change. In this sense as well, it is therefore an imposter that misleads by association with trendy phrases and ideas.

In contrast to global competency defined as a set of skills and knowledge useful in a globalised economy and labour market, global citizenship refers to individuals empowered by a broader knowledge of the wider world that contributes to their intellectual abilities of problem-solving and critical thinking, and most importantly a strong sense of social responsibility from an unbiased global perspective. (Ouyang \& McAlpine, 2013, p. 10. Italics added) 
Thus, as Ş. İlgu Özler (2013, p. 13) claims, "we need a new cosmopolitan vision, with a common human identity and a sense of global citizenship displacing our understanding of relations between citizens of 'foreign' countries." To achieve such a condition requires states to embrace the situation in which they are willing to relinquish their hold on nationalistic educational ideals so as to allow their citizens to see the bigger and, I would argue, more important, picture. If Japanese society is to embrace multiculturalism, the trend towards global jinzai offers potential and possibilities towards creating a required social and mental framework. However, multiculturalism or global citizenship are not the ultimate goal of many who promote the global jinzai debate. Once the ultimate goal of global jinzai is explained thus, it becomes easier to understand why, in spite of discussions, symposiums, policies, plans, and ongoing debates, in this undeveloped immature state it will likely never realize its full potential under present circumstances in Japan.

\section{Notes}

1. Author's translation. For the full report, see: http://www.jsps.go.jp/ j-tenkairyoku/data/meibo_siryou/h23/ sankou06.pdf.

2. Author's translation. For the report see: Nikkeiren Kyōiku Tokubetsu Iinkai 1997.

3. The five goals are: improving foreign language ability through the use of entrance exams and classes, increasing overseas study and exchange opportunities, strengthening teachers' global educational ability, offering flexibility in entrance and graduation times, and increasing the number of foreign teachers.

4. The Global 30 (G30) project aims to contribute to the globalization of Japanese higher education by selecting 30 universities to act as centres of globalization by predominantly offering courses in English for international students.

\section{References}

Ashizawa, S. (2012). Why now? Global jinzai and gap year. Paper presented at Meiji University Research Institute of International Education Inaugural International Symposium Series 3, Tokyo. Retrieved from http://www.british council.jp/sites/ britishcouncil.jp/files/edu-ashizawa-meiji-university.pdf.

Chapple, J. (2002). Japan's policy of internationalisation: Prospects for a multicultural society (Ph.D. dissertation). Victoria University of Wellington, New Zealand.

Knight, J. \& Altbach, P. (2007). The internationalization of higher education: Motivations and realities. Journal of Studies in International Education, 11, 290-305.

Lie, J. (2004). Multiethnic Japan. Cambridge: Harvard University Press. 
Maher, J. C. \& Yashiro, K. (Eds) (1995). Multilingual Japan. Clevedon, UK: Multilingual Matters.

Ministry of Economy, Trade and Industry [METI] (2011). Mid-term report from the council on the promotion of global human resources. Retrieved from http://www. meti.go.jp/policy/ economy/jinzai/san_gaku_kyodo/sanko1-1.pdf.

Ministry of Education, Culture, Sports, Science and Technology [MEXT] (2012). Daigaku kaikaku jikkō puran. [The plan to change universities]. Retrieved from http://www.mext.go.jp/b_menu/houdou/24/06/_icsFiles/afieldfile/ 2012/06/25/1312798_01.pdf.

Ministry of Education, Science and Culture (1999). Japanese government policies in education, science, sports and culture 1999: Educational reform in progress. Tokyo: Ministry of Education, Science, Sports and Culture Japan.

NIER [National Institute for Educational Policy Research] (2011). International student policy in Japan. In Education in Japan. Retrieved from http://www.nier. go.jp/ English/EducationInJapan/Education_in_Japan/Education_in_Japan_ files/201203IntlSt.pdf

Nihon Keizai Shimbun (2012, December 21). Jinzai kyōsō kokkyō naku uchimuki kaeru kōki ni [A good opportunity to change from unward-looking].

Nihon Keizai Shimbun (2013a, January 18). Kyōin kōsō "uchimuki" yabure [It's faculty who need to break the "inward-looking" mentality].

Nihon Keizai Shimbun (2013b, February 9). Kaigai ryūgaku 6nen renzoku gen [The number of students studying abroad falls for the 6th straight year].

Nihon Keizai Shimbun (2013c, April 21). Gaikokujin kyōin 1man nin ni [Increase the number of foreign faculty to 10,000].

Nikkeiren K. T. I. (1997). Gurōbaru shakai ni kōken suru jinzai no ikusei o [Towards to development of human resources capable of contributing to a global society]. Tokyo: Nihon Keiei sha dantai remei Kyoiku bu.

OECD (2012). How many students study abroad and where do they go? In Education at a glance 2012: Highlights, OECD publishing (pp. 24-27). Retrieved from http://dx.doi.org/ 10.1787/eag_ highlights-2012-9-en.

Oka, Y. (2013, August 16). Kokusaijin yōsei ni "global kō" monkashō 100 ko shitei e [To develop international people MEXT plans to select 100 "global schools"]. Asahi Shimbun. Retrieved from http://www.asahi.com/edu/articles/ TKY20130814043 2.html

Ouyang, G. \& McAlpine, S. (2013). Global competency is not enough: Attaining global citizenship. In EAIE summer forum: Discussing international education: Social responsibility (pp. 8-10). Amsterdam: European Association for International Education.

Ş. İlgu Özler (2013). Global citizenship versus diplomacy: Internationalisation of higher education with a collective consciousness. In A. Labi (Eds), Weaving the future of global partnerships (pp. 13-18). Amsterdam: European Association for International Education.

Pollock, S. (2012). Cultivating "global jinzai" critical to Japan's international success. Turnstone Ventures. Retrieved from http://www.turnstoneventures.com/ cultivating_global_jinazi.html.

Sankei S. (2012, August 12). Sankangaku kyōdō de gurōbaru jidai ni tekiō [Government, industry and universities working together to adapt to the global age].

Sawa, T. (2013, June 24). Commentary: Top students shunning Japan. The Japan Times. 
The Japan Times (2013, June 16). Editorials: Too many inward-looking students. Retrieved from http://www.japantimes.co.jp/opinion/2013/06/16/editorials/ too-many-inward -looking-students/\#.Ucf7F81bBD.

Except where otherwise noted, this work is licensed under a Creative Commons Attribution 3.0 Unported License. To view a copy of this license, visit http://creativecommons.org/licenses/by/3.0/ 